International Journal of Trend in Scientific Research and Development (IJTSRD)

Volume: 3 | Issue: 3 | Mar-Apr 2019 Available Online: www.ijtsrd.com e-ISSN: 2456 - 6470

\title{
Design and Developing of Two-Wheeler Handle Gripper Using 3D Printing Technology
}

\author{
S. Suresh'1, Duppelly Vamshi², Boda Rahul2 ${ }^{2}$, Dharavath Ashok Kumar ${ }^{2}$ \\ ${ }^{1}$ Assistant Professor, ${ }^{2}$ Student \\ 1,2Department of Mechanical Engineering, Guru Nanak Institute of Technology, Hyderabad, India
}

\begin{abstract}
How to cite this paper: S. Suresh | Duppelly Vamshi | Boda Rahul | Dharavath Ashok Kumar "Design and Developing of Two-Wheeler Handle Gripper Using 3D Printing Technology" Published in International Journal of Trend in Scientific Research and Development (ijtsrd), ISSN: 24566470, Volume-3 | Issue-3 , April 2019, pp.1173-1175, URL: https://www.ijtsrd.c om/papers/ijtsrd23 311.pdf

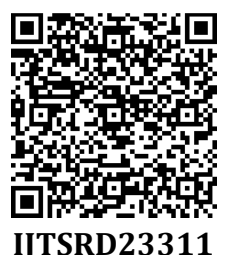

Copyright (C) 2019 by author(s) and International Journal of Trend in Scientific Research and Development Journal. This is an Open Access article distributed under the terms of the Creative Commons

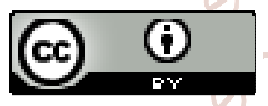
Attribution License (CC BY 4.0) (http://creativecommons.org/licenses/ by $/ 4.0$ )

\section{Introduction}

Grippers are the devices that hold the equipment or part of machine in order to provide better holding experience to consumers of devices, these are used in different machines like automobiles and small components etc. In case of twowheeler handle grippers plays an important role in speed control of vehicle.

In generals these grippers are fabricated by injection moulding and other conventional fabrication methods, this method of fabrication process provides better quality, but it is time consuming process and defects generation problem will arise in this process so in this project rapid prototyping technology is used.

Rapid prototyping technology provides better quality to products and less processing time. In this technology different methods are there best for production of this gripper's id fused deposition method. This process involves the lay-by layer application of materials according to model created in this software.

For this project CATIA V5 is used as modeling tool in order to create 3D model of handle grippers on basis of requirement and dimensions of handle where it is placed. 3D printer is used to produce final product on basis of design provided to printer from Idea Maker software.

Computer aided drafting reduces the cost of testing of product after production because it includes analysis tool to solve this problem. 3D printed parts are analyzed by this method without breaking it [1], 3D printed casting parts are used in the replacement of tradition casted parts, it reduces the steps involved in the traditional process and time taken for fabrication also be less [2], complex shapes and geometries are difficult to produce by using traditional method but 3D printing technology produce complex shapes also with benefits of large mass reduction and material usage minimum in production [3].

\section{Materials}

For TWHG fabrication process different materials are used like plastics etc, but fabrication by using these materials is difficult compared to fused deposition method. Generally, for 3D printing purpose different materials like plastics, ceramics and other materials are used in powder or wire as shown in Fig.1. form, polylactic acid (PLA) is selected for fabrication because its is famous for moulding purposes and it provides firm grim if it is directly used. 


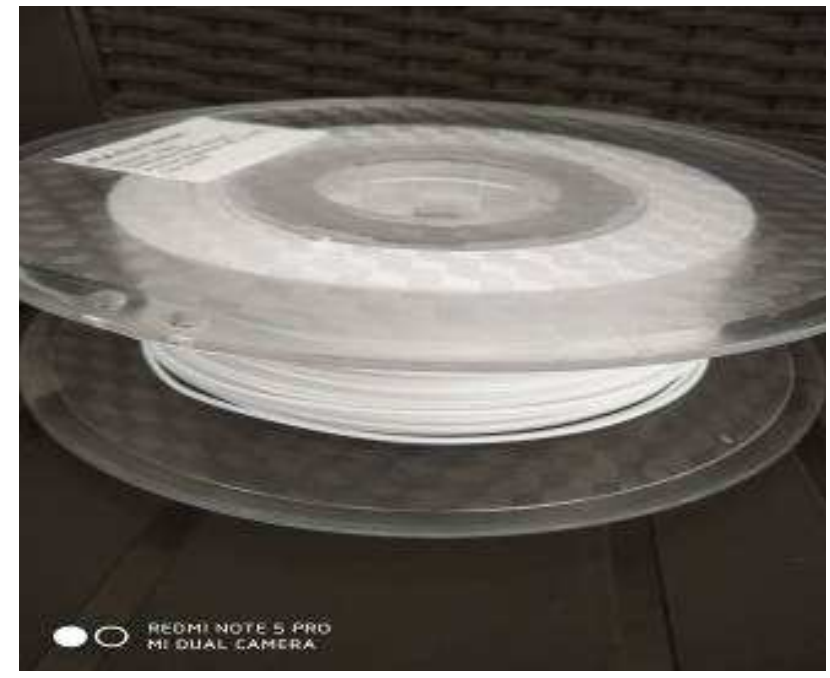

Fig.1. PLA Material

III. Methodology

Methodology of two-wheeler handle grippers fabrication design and modelling involves different stages like selection of material, collection of design parameters, modelling of handle grippers, conversion of file to standard tessellation language format and finally 3D printing of TWHG as shown in Fig.2.

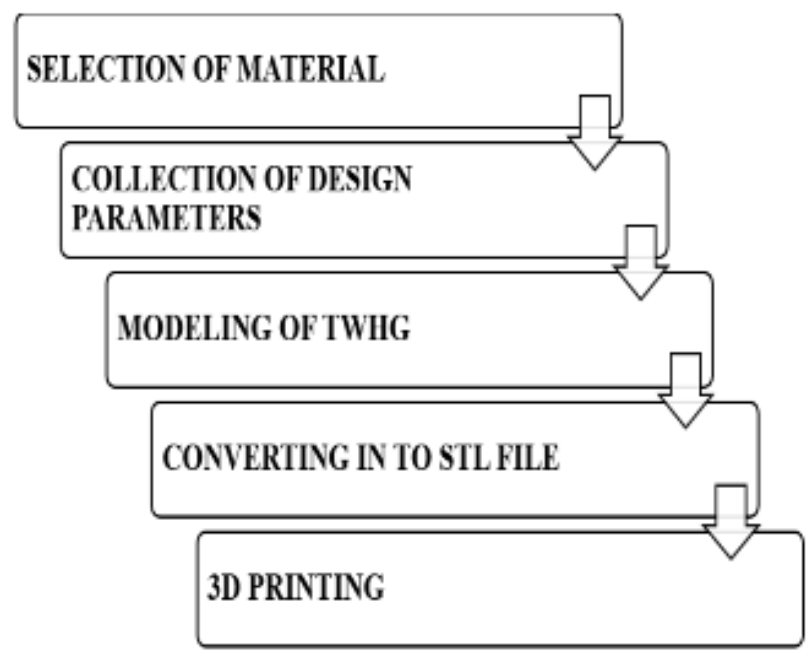

Fig.2. Methodology of TWHG

Selection of material for any production purpose depends on their application, where they are applied in real practice, what are properties needed for that application. For design of TWHG data must be collected like diameter, length and gripping area these data is necessary for design and modelling of TWHG.

After model creation that file converted into STL file format and sent to 3D printer for production.

\section{Modelling of Two-Wheeler Handle Grippers}

Handle gripper model is created by using CAD software CATIA V5R20, this is fully three-dimensional software. this software was extensively used in the design of the mirage aircraft, however of the software soon made it a popular choice in the automotive sector as well. As CATIA was accepted by more manufacturing companies. This software can be used at different stages of the design-ideate, draw, test and iterate.

\section{Steps for 3D model Production}

$>$ Select the plane on which the design needs to be drawn.

$>$ Select sketcher it is used to create $2 \mathrm{D}$ representation of part and draw two circles as shown in Fig.3.

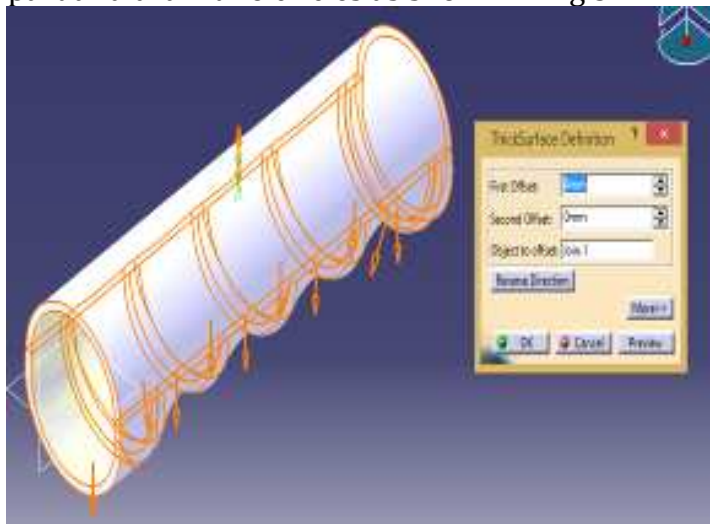

Fig.3. Sketching of TWHG

$>$ After creating profile exit from workbench and enter part design.

$>$ By using pad option add material to profile of handle gripper and set height as shown in Fig.4.

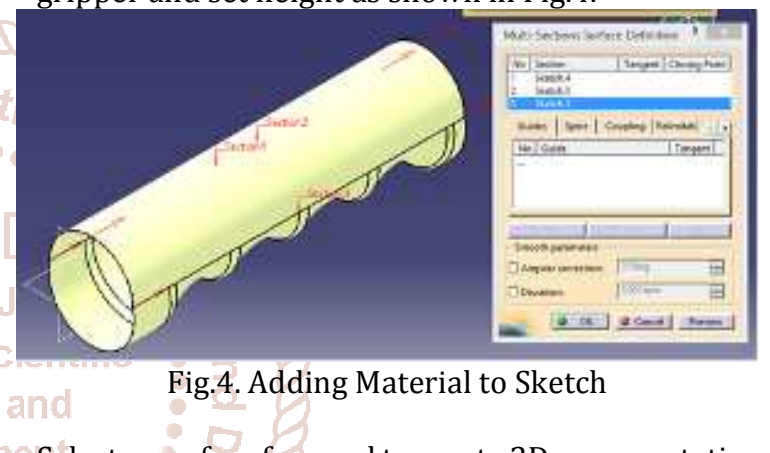

Select one of surface end to create 2D representation of part and draw circle.

$>4$ After creating profile exit from workbench and enter part design.

$>$ By using pad option add material to profile of handle gripper and set thickness.

Select another surface of handle gripper, create 2D representation of part and set thickness.

$>$ By using pad option add material to profile of handle gripper and set thickness.

$>$ Select cylindrical surface to create 2D representation of part and draw profile.

$>$ Finally, by using slot option make slot inside hole at angle of 30 degree created by pocket on the handle gripper. Final modelled handle gripper as shown in Fig.5.

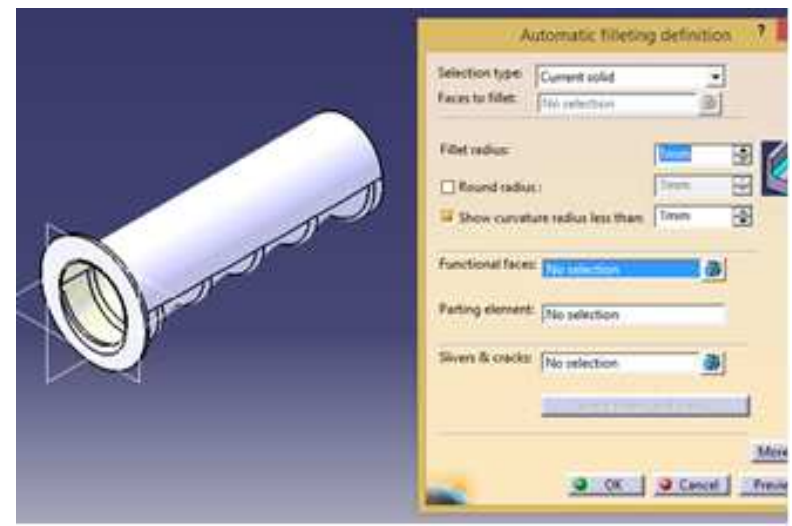

Fig.5. Final Model of TWHG 


\section{Fabrication of Handle Grippers}

Fabrication of TWHG involves different steps like selection of material, model creation, format conversion and fused deposition process. PLA is selected for fabrication of handle grippers and after creation of model in CATIA V5 software it converts like STL file.

STL file is opened in IdeaMaker software for slicing as shown in Fig.6. of modelled handle grippers, slicing is necessary in order to get better product from 3D printer as shown in Fig.7, final product as shown in Fig.8.

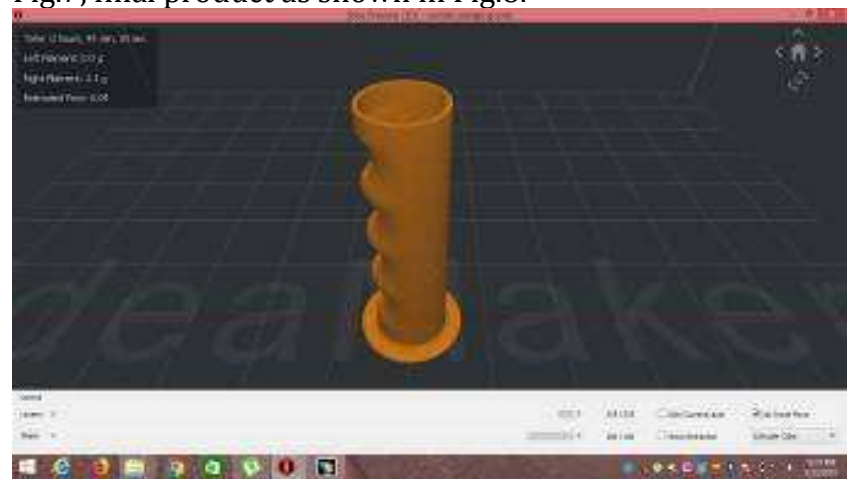

Fig.6. Importing Model to IdeaMaker Software

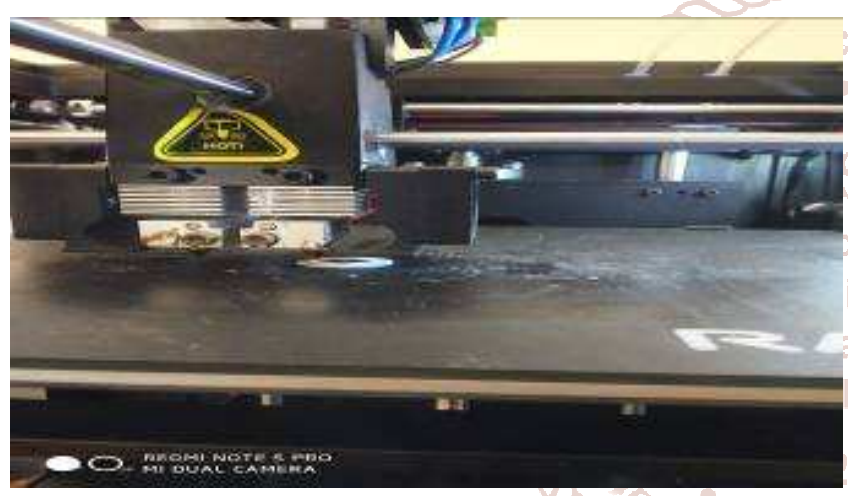

Fig.7. 3D Printing of TWHG

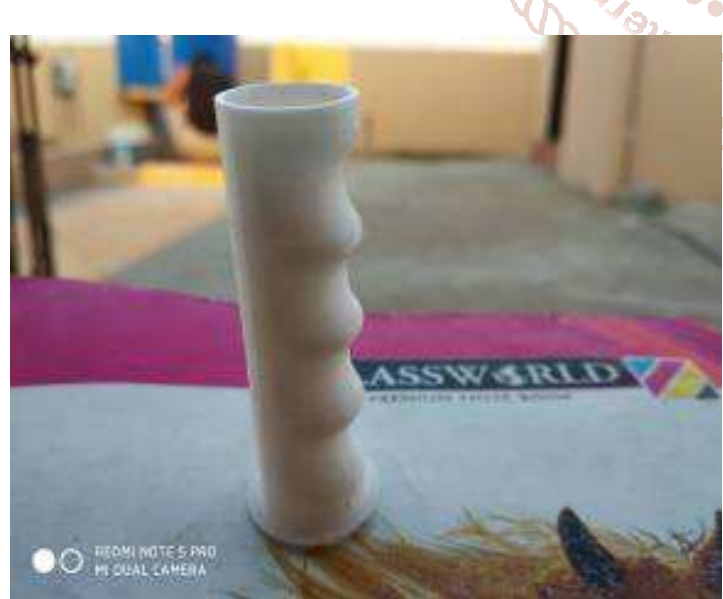

Fig.8. Final Product

\section{Conclusion}

From this project it concluded that fabrication of twowheeler handle grippers by using traditional methods takes more time for production and skilled person is required for production process.

By using $3 \mathrm{~d}$ printers these problems are reduced to some extent like time taken for fabrication process is less compared to traditional process, it provides better quality to product and, gives better dimensional accuracy within a short period of time.

These grippers are not having smooth surface, by using rubber cover on to its surface it is better to use in twowheeler handles.

\section{Acknowledgment}

I heart fully thank Dr. B. Vijaya Kumar, professor and head of department, Guru Nanak Institute of Technology for his constant encouragement.

I extended my deep sense of gratitude to the principle Dr. S. Sreenatha Reddy and the management of Guru Nanak Institute of Technology for providing of the best amenities to enable us to complete my project in stipulated time.

\section{References}

[1] Engr. Rufus Ogubuka Chime "Design Modelling, Simulation of Spur Gear; Analysis of Spur Gear" International Journal of Engineering Research and Development Vol. 12, No. 1, 2016, pp. 56-67.

[2] ICHIDA, Yozi "Current Status of 3D Printer Use Among Automotive Suppliers: Can 3D Printed-parts Replace Cast Parts" IFEAMA SPSCP Vol. 5, pp. 69-82.

[3] V. Sreehitha "Impact of 3D Printing in Automotive Industries" International Journal of Mechanical and Production Engineering Vol. 5, No. 2, 2017, pp. 91-94 